\title{
Editorial: Biomarkers and Clinical Indicators in Motor Neuron Disease
}

\author{
Peter Bede ${ }^{1,2,3 *}$ and Pierre-Francois Pradat ${ }^{2,3+}$ \\ ${ }^{1}$ Computational Neuroimaging Group, Trinity College Dublin, Dublin, Ireland, ${ }^{2}$ Department of Neurology, Pitié-Salpêtrière \\ University Hospital, Paris, France, ${ }^{3}$ Sorbonne University, CNRS, INSERM, Biomedical Imaging Laboratory, Paris, France
}

Keywords: ALS, MND, PLS, SMA, SBMA, PPS, PMA, biomarker

\section{Editorial on the Research Topic}

Biomarkers and Clinical Indicators in Motor Neuron Disease

Motor neuron diseases (MNDs) encompass a range of progressive neurodegenerative conditions with heterogeneous clinical presentations, disability profiles, prognosis, and age of onset. The umbrella term MND typically includes amyotrophic lateral sclerosis (ALS) (1), primary lateral sclerosis (PLS) $(2,3)$, progressive muscular atrophy (PMA), hereditary spastic paraplegia (HSP), spinal muscular atrophy (SMA) $(4,5)$, spinal and bulbar muscular atrophy (SBMA) (6), and rare conditions such as monomelic amyotrophy (MMA), juvenile muscular atrophy of distal upper extremity (JMADUE) (7), Mill's disease (8), ALS-FTD complex (9), and progressive bulbar palsy (PBP) (10). Despite the diversity of the clinical phenotypes, MNDs share a number of fundamental traits such as a long presymptomatic phase (11), insidious onset (12), considerable diagnostic challenges $(13,14)$, relatively low incidence $(15,16)$, extra-motor (Christidi et al.; Christidi et al.) and extra-neurological manifestations (6), relentless progression (17, 18), multidisciplinary care needs $(19,20)$, and lack of effective disease modifying therapies. These core similarities justify the discussion of various MNDs in a dedicated collection of articles and offer the opportunity to exchange research ideas between centres focusing on specific MNDs. There are other shared challenges across the MND spectrum, which are particularly relevant for therapy development, chief of which is the lack of validated biomarkers to serve as outcome measures in clinical trials. Pharmaceutical trials in MNDs mostly rely on functional rating scales and survival instead of objective, observer-independent markers which reflect on the underlying pathology of the condition $(1,21,22)$.

\section{INTRODUCTION}

The dual relevance of biomarker development in MND lies in the characterization of dynamic pathological processes and its application to individualized patient care. From an academic perspective, biomarkers have the potential to elucidate the role of specific pathophysiological mechanisms, such as inflammation, cortical hyperexcitability, inhibitory dysfunction, cell to cell propagation and anatomical patterns of vulnerability. From a clinical standpoint, validated biomarkers have the potential to confirm an earlier diagnosis, thus enabling recruitment into clinical trials at an earlier stage. The key advantage of biomarkers however is their potential monitoring role in clinical trials; tracking disease progression in vivo and potentially detecting response to therapy. Biomarkers may also act as prognostic indicators which are indispensable both for patient stratification in clinical trials as well as individualized patient care.

The academic and clinical importance of biomarker development in MND is universally recognized by various scientific consortia and is regarded as a strategic funding priority by MND charities and funding agencies around the world. MNDA, ALSA, ARSLA, NISALS, NEALS, CALSNIC, RMN, JPND, IMNDA, SPF etc. are just some of the many organizations actively 
engaging in the development of multicenter data repositories, and establishing biobanking infrastructures for MND. Due to the limitations of single markers, it is generally accepted that a panel of biomarkers will most likely aid clinical management, guide care planning, and serve as monitoring markers in clinical trials. It is also increasingly clear that precision individualized therapies will be needed for specific phenotypes and genotypes instead of a "one-drug-for-all” approach.

The main themes of MND biomarker research include "wet biomarkers" which focus on disease-specific biofluid profiles and "dry biomarkers" such as electrophysiological and neuroimaging measures. Hypothesis-driven, targeted and highthroughput methods are both widely used in the so-called "omics" approaches: metabolomics, proteomics, lipidomics, and transcriptomics. One of the alluring aspects of international collaborations is that MND centers around the world have unique local expertise profiles which complement synergistically the skillset of other centers. Therefore, single ALS centers are in a position to provide authoritative reviews on specific aspects of biomarker research efforts. The editors of this collection are grateful for the expert contribution of 37 renowned research centers from around the globe. The 37 research papers included in this Research Topic discuss specific aspects of biomarker development in motor neuron diseases and embrace the diversity of MND phenotypes from SBMA to ALS-FTD. While the methodological focus of the papers differs depending the expertise profile of the authors, there is a cohesive theme among the papers to appraise biological, molecular, electrophysiological, and radiological markers which may potentially serve as pragmatic clinical indicators confirming the diagnosis, predicting the prognosis, detecting response to therapy or track longitudinal neurodegenerative changes. Beyond the practical relevance of ascertaining and quantifying pathological changes in vivo, biomarkers in MND also provide considerable academic insights such as the exploration of presymptomatic changes $(23,24)$, the description of genotype-associated signatures $(25,26)$, the delineation of natural disease trajectories $(11,27)$, the characterization of low-incidence phenotypes $(2,28,29)$, confirmation of epigenetic and epidemiological factors $(30,31)$, and deciphering the pathological substrate of clinical symptoms [Finegan et al.; $(32,33)$ ].

One of the commonest adult-onset motor neuron diseases is amyotrophic lateral sclerosis (ALS) which is an archetypical neurodegenerative condition with a presumed long presymptomatic phase (34), considerable delay between symptom onset and definite diagnosis (35), significant individual variations in disability profiles (Yunusova et al.), unrelenting motor decline (36), widespread non-motor symptoms $(37,38)$, and complex genetics $(39,40)$. In this collection of papers (https://www.frontiersin.org/research-topics/7659/biomarkersand-clinical-indicators-in-motor-neuron-disease) wet and dry biomarkers are equally represented. "Wet" biomarkers typically refer to spinal fluid, serum or tissue-based indicators, whereas "dry" markers indicate non-invasive radiological, neuropsychological and or clinical indicators (41).

\section{WET BIOMARKERS}

Two papers are dedicated to the academic and biomarker role of micro RNAs; Joilin et al. discuss the diagnostic and prognostic utility of specific microRNAs and Rob Layfield's group propose the targeted study of four miRNAs; hsamiR-124-3p, hsa-miR-127-3p, hsa-let-7a-5p, and hsa-miR-9$5 \mathrm{p}$ as particularly promising biomarkers (Foggin et al.). Tan and Guillemin discuss the potential biomarker role of kynurenine pathway metabolites in ALS, as these are involved in inflammation, excitotoxicity, oxidative stress, immune responses, and energy dysregulation. Chen et al. base their study on the inflammatory hypothesis of ALS etiology and not only demonstrate increased IL-6 levels in astrocyte-derived exosomes in ALS patients but identify associations with rate of progression. Dr. Duguez's group meticulously reviews the literature and suggest a multi-tissue biomarker panel encompassing markers of motor neuron integrity ( $\mathrm{pNFH}$ and NF-L, cystatin C, Transthyretin), inflammation (MCP1, miR451), muscle integrity (miR-338-3p, miR-206) and metabolism (homocysteine, glutamate, cholesterol). They argue that biomarker panels should reflect the multi-system, multitissue nature of ALS-pathophysiology (Vijayakumar et al.). As ALS is increasingly recognized as a metabolic disorder (42), De Aguilar provides an eloquent overview of metabolic markers with a particular focus on proposed lipid biomarkers. Kirk et al. elaborate on the metabolic spectrum of ALS from cellular to multi-organ systemic involvement. Dr. Blasco's team discusses advances in metabolomics and advocates for a pharmacometabolomic approach to evaluate individual response to therapy, to develop personalized treatments for ALS (Lanznaster et al.). Poesen and Van Damme review the diagnostic, monitoring and prognostic role of neurofilaments in ALS.

\section{CLINICAL INDICATORS AND THERAPEUTIC STRATEGIES}

Zhang et al. draw the reader's attention to comorbid extraneurological manifestations in ALS, such as autoimmune syndromes. Lule et al. contribute an authoritative review of the key determinants of quality of life in ALS, and underline the lack of a direct link between physical disability and quality of life. Professors Lule and Ludolph also emphasize the key ethical principles of supportive care in ALS which are centered on patient autonomy, dignity, beneficence and caregiver support (20, 43-47). Li Hi Shing et al. highlight the complex symptomatology of post-polio syndrome and discuss the etiology of under-researched symptoms such as fatigue. Finegan et al. perform a comprehensive review of the pathophysiology of pseudobulbar affect (pathological crying and laughing) which is one of the most prevalent and distressing symptoms of PLS and ALS, yet it remains surprisingly understudied $(32,33,48)$. Chipika et al. undertake a systematic analysis of the most promising markers to track pathological progression in vivo, which may detect response to therapy in future clinical trials of 
ALS. Their primary perspective is the assessment of the pragmatic utility [Grollemund et al.; (14, 35, 49-51)] of emerging markers in pharmaceutical trials (Chipika et al.). Christidi et al. reviews the evidence for memory deficits in MND with a painstaking analysis of the available clinical (52), radiological (1) and post mortem literature (53). Professor Mioshi's group eloquently reviews the impact of cognitive and behavioral deficits in ALS on patients and caregivers drawing attention to an important aspect of ALS care which is relatively understudied $(54,55)$. The novelty of their analysis lies in the identification of viable non-pharmaceutical strategies to improve patient and caregiver well-being (Caga et al.). Grollemund et al. perform an in-depth analysis of the ever expanding literature of machine-learning in MND, and discuss the advantages and drawbacks of specific mathematical models. Professor de Carvalho's group gives an authoritative overview of respiratory markers and diaphragmatic neurophysiology in ALS (de Carvalho et al.). Professor Yunosova's group appraises the most commonly utilized clinical tools for assessing and monitoring bulbar dysfunction in ALS and advocate for the development and validation of novel assessment protocols (Yunosova et al.). Professor Kabashi's group gives an elegant overview of neuromuscular junction involvement in ALS and examines the evidence from animal models to clinical observations (Campanari et al.). Dr. Floeter's group discuss genotype-specific biomarker panels and presymptomatic alterations. They review candidate imaging, electrophysiology, and biofluid markers in patients with C9orf72 hexanucleotide expansions (Floeter et al.). Christidi et al. discuss the clinical (38, 56-58), imaging $(31,36,59,60)$, and pathological correlates of cognitive and behavioral dysfunction in ALS giving specific screening and assessment recommendations. They describe which domains are most likely to be affected and review the impact of neuropsychological deficits on patients and their caregivers (Christidi et al.). Querin et al. evaluate monitoring strategies in spinal and bulbar muscle atrophy (SBMA) and discuss the spectrum of motor, extra-motor, and extra-neurological manifestations in detail. They give specific recommendations to screen for endocrine, cardiac and respiratory involvement (Querin et al.).

From a therapeutic viewpoint, Gouel et al. discuss the role of neurotrophic growth factors (NTF) in neuroprotection and neurorestoration. Professor Bogdahn's group give a reallife example of using biomarkers in a therapeutic trial of Granulocyte-colony stimulating factor (G-CSF). They evaluate the biomarker potential of serum cytokines in ALS and perform a meticulous analysis of MDC, TNF-beta, IL-7, IL-16, and Tie-2 levels in relation to clinical outcomes (Johannesen et al.).

\section{DRY BIOMARKERS}

Electrophysiology is one of the most widely utilized clinical and research tools in motor neuron diseases [Proudfoot et al.; $(5,61,62)]$. Professor Kiernan's group provides an expert review of electrophysiological markers of upper and lower motor neuron degeneration and discuss the clinical value of specific neurophysiological indices (Huynh et al.). Wang et al. present an elegant electrophysiology study, investigating the neurophysiological substrate of the split-hand phenomenon. Imaging is another promising dry biomarker of ALS-associated degenerative change. In recent years imaging in ALS confirmed extensive extra-motor pathology in cerebellar $(63,64)$, extrapyramidal $(65,66)$, subcortical $(26,67)$, hippocampal [Christidi et al.; $(68,69)$ ], hypothalamic $(42)$, brainstem [Yunusova et al.; (70)], and frontotemporal involvement [Christidi et al.; (71)]. Imaging in ALS also helped to decipher the pathological underpinnings of specific symptoms, such as pseudobulbar affect [Finegan et al.; $(32,33,48)]$, compensatory changes (72), executive dysfunction (73), extrapyramidal manifestations (65), metabolic dysfunction (42), memory deficits $(59,74)$. Imaging in ALS has also been instrumental to link disability profiles to pathological TDP-43 burden patterns $(36,53,75-78)$ and track progressive pathological changes [Chipika et al.; $(11,79)]$. In this collection of papers, Fortanier et al. demonstrate how structural imaging data may be used to characterize alterations in connectivity patterns. Rajagopalan and Pioro elegantly demonstrate how clinically well-defined ALS sub-populations have distinctive neuroimaging signatures. Instead of the most commonly used quantitative techniques, such as diffusion tensor imaging $(80,81)$ they demonstrate the utility of alternative imaging cues on T2-wighted, Flair and proton density imaging (Rajagopalan and Pioro). Kalra a pioneer of MR spectroscopy, gives an eloquent overview of the achievements, practical utility and future applications of metabolic imaging in ALS. Professor Filippi and Dr. Agosta's research group contributed an expert review of diffusion imaging in ALS, discussing methodological advances, the contribution of network analyses, and the potential of DTI to track progressive pathological changes (Basaia et al.). Their observations also highlight the paradigm shift from the analysis of focal diffusivity changes $(80,81)$ to the assessment of network integrity $(41,82)$. Muller and Kassubek review the utility of diffusion tensor imaging in ALS with respect to detecting pathological TDP-43 burden in vivo. They describe how in vivo measurements may relate to pathological stages and provide an expert overview of the most frequently utilized analysis methods (Muller and Kassubek). The majority of imaging studies in motor neuron disease focus on cerebral pathology $(72,83-85)$, despite the pathognomonic involvement of the spinal cord in ALS [El Mendili et al. (86)], SBMA $(6,10)$, SMA (4, 5), PLS (2), juvenile muscular atrophy of distal upper extremity $(7,28,87)$ and PPS (29). In this Research Topic, Professor Pradat's group gives a methodological update on advances in spinal imaging and outline future research directions (El Mendili et al.). Chew and Atassi discuss how PET radioligands unveil specific pathophysiological mechanisms such as neuroinflammation, metabolic changes, neuronal dysfunction, and oxidative stress and how PET may be utilized both in natural history studies and pharmaceutical trials. Professor Turner's group reviews the advances in functional imaging discussing the contribution of functional MRI, MEG and EEG studies to ALS research (Proudfoot et al.). Dr. Grosskreutz's group discusses the benefits of data sharing and gives an expert overview of the methodological and logistical challenges of data harmonization, hosting large data repositories, generating consortium bylaws and data protection policies (Steinbach et al.). Barritt et al. summarize some of the most exciting new imaging 
methods in MND and discuss emerging methods such as Neurite Orientation Dispersion and Density Imaging (NODDI) (88), and quantitative Magnetization Transfer Imaging (qMTi) and data analysis approaches such as Event-Based Modeling (EBM). A shared aspiration of both "wet" and "dry" biomarker studies is the transition from describing group-level observations to the precision categorization and tracking of individual patients $(53,76,83,84,89-91)$.

\section{CONCLUSIONS}

The ensemble of these articles showcases the determination, drive and momentum in motor neuron disease research worldwide. We are particularly proud that renowned research groups from Australia, France, China, Greece, United Kingdom, Ireland, United States, Canada, Germany, Belgium and Italy shared their unique perspective, methodological expertise and their vision for future research directions. The diversity of research strategies and the unrelenting enthusiasm of the various research groups give cause for optimism for the development of precision biomarkers, and ultimately, a cure for MND.

\section{AUTHOR CONTRIBUTIONS}

Both authors contributed equally to the drafting of this editorial.

\section{FUNDING}

PB was supported by the Health Research Board (HRBIreland; HRB EIA-2017-019), the Andrew Lydon scholarship, the

\section{REFERENCES}

1. Turner MR, Agosta F, Bede P, Govind V, Lule D, Verstraete E. Neuroimaging in amyotrophic lateral sclerosis. Biomark Med. (2012) 6:31937. doi: $10.2217 / \mathrm{bmm} .12 .26$

2. Finegan E, Chipika RH, Shing SLH, Hardiman O, Bede P. Primary lateral sclerosis: a distinct entity or part of the ALS spectrum? Amyotroph Lateral Scler Frontotemporal Degener. (2019) 20:133-45. doi: 10.1080/21678421.2018.1550518

3. Finegan E, Chipika RH, Li Hi Shing S, Doherty MA, Hengeveld JC, Vajda A, et al. The clinical and radiological profile of primary lateral sclerosis: a population-based study. J Neurol. (2019). 266:2718-33. doi: 10.1007/s00415-019-09473-z

4. Querin G, El Mendili MM, Lenglet T, Behin A, Stojkovic T, Salachas F, et al. The spinal and cerebral profile of adult spinal-muscular atrophy: a multimodal imaging study. NeuroImage Clin. (2019) 21:101618. doi: 10.1016/j.nicl.2018.101618

5. Querin G, Lenglet T, Debs R, Stojkovic T, Behin A, Salachas F, et al. The motor unit number index (MUNIX) profile of patients with adult spinal muscular atrophy. Clin Neurophysiol. (2018) 129:2333-40. doi: 10.1016/j.clinph.2018.08.025

6. Querin G, Bede P, Marchand-Pauvert V, Pradat PF. Biomarkers of Spinal and Bulbar Muscle Atrophy (SBMA): a comprehensive review. Front Neurol. (2018) 9:844. doi: 10.3389/fneur.2018.00844

7. Bede P, Bokde AL, Byrne SC, Elamin M, Walsh RJ, Hardiman O. Waterskier's Hirayama syndrome. J Neurol. (2011) 258:2078-9. doi: 10.1007/s00415-011-6046-5
Irish Institute of Clinical Neuroscience IICN-Novartis Ireland Research Grant, the Iris O'Brien Foundation, and the Research Motor Neuron (RMN-Ireland) Foundation. P-FP was supported by the French Association for Myopathies (AFM-Telephon), the Institute for Research in Brain and Spinal Cord (IRME) the French Association for Research in ALS (ARSLA) and the Target ALS Foundation.

\section{ACKNOWLEDGMENTS}

We acknowledge all patients with motor neuron disease, their caregivers, family members, neurologists, basic scientists, and allied health care professionals around the globe who participate in motor neuron disease research. We also acknowledge the contribution of authors from the following universities and research centers; University of Sussex, University of Athens, Aix Marseille University, Harvard Medical School, Macquarie University Sidney, University of Oxford, Hebei Medical University Shijiazhuang, Lille University, Trinity College Dublin, Cleveland Clinic, University of Sydney, University of Nottingham, Peking University, Northern Ireland Center for Stratified Medicine, University of Alberta, Chinese Academy of Medical Sciences, Icahn School of Medicine at Mount Sinai, University of Strasbourg, Sorbonne University, University of Ulm, The University of Queensland, University of Sydney, University of East Anglia, Vita-Salute San Raffaele University, University of Lisbon, University of Toronto, University Hospitals Leuven, University of Tours, National Institutes of Health US, Mayo Clinic, University of Jena, Brighton and Sussex Medical School, University of Regensburg.

8. Turner MR, Gerhard A, Al-Chalabi A, Shaw CE, Hughes RAC, Banati RB, et al. Mills' and other isolated upper motor neurone syndromes: in vivo study with 11C-(R)-PK11195 PET. J Neurol Neurosurg Psychiat. (2005) 76:871-4. doi: 10.1136/jnnp.2004.047902

9. Omer T, Finegan E, Hutchinson S, Doherty M, Vajda A, McLaughlin RL, et al. Neuroimaging patterns along the ALS-FTD spectrum: a multiparametric imaging study. Amyotroph Lateral Scler Frontotemporal Degener. (2017) 18:611-23. doi: 10.1080/21678421.2017.1332077

10. Hardiman O, Doherty CP, Elamin M, Bede P. Neurodegenerative Disorders: A Clinical Guide. Cham; Heidelberg; New York, NY; Dordrecht; London: Springer (c) Springer International Publishing Switzerland 2016: Springer International Publishing (2016). p. 1-336. doi: 10.1007/978-3-31923309-3

11. Schuster C, Elamin M, Hardiman O, Bede P. Presymptomatic and longitudinal neuroimaging in neurodegeneration-from snapshots to motion picture: a systematic review. J Neurol Neurosurg Psychiat. (2015) 86:1089-96. doi: 10.1136/jnnp-2014-309888

12. Hardiman O, Al-Chalabi A, Chio A, Corr EM, Logroscino G, Robberecht W, et al. Amyotrophic lateral sclerosis. Nat Rev Disease prim. (2017) 3:17071. doi: $10.1038 /$ nrdp. 2017.85

13. Hardiman O, van den Berg LH, Kiernan MC. Clinical diagnosis and management of amyotrophic lateral sclerosis. Nat Rev Neurol. (2011) 7:63949. doi: 10.1038/nrneurol.2011.153

14. Bede P, Iyer PM, Finegan E, Omer T, Hardiman O. Virtual brain biopsies in amyotrophic lateral sclerosis: diagnostic classification based on in vivo pathological patterns. NeuroImage Clin. (2017) 15:653-8. doi: 10.1016/j.nicl.2017.06.010 
15. Byrne S, Walsh C, Lynch C, Bede P, Elamin M, Kenna K, et al. Rate of familial amyotrophic lateral sclerosis: a systematic review and meta-analysis. J Neurol Neurosurg Psychiat. (2011) 82:623-7. doi: 10.1136/jnnp.2010. 224501

16. Byrne S, Heverin M, Elamin M, Bede P, Lynch C, Kenna K, et al. Aggregation of neurologic and neuropsychiatric disease in ALS kindreds: a population based case controlled cohort study of Familial and Sporadic ALS. Ann Neurol. (2013) 82:457-65. doi: 10.1002/ana.23969

17. Bede $\mathrm{P}$, Hardiman $\mathrm{O}$. Longitudinal structural changes in ALS: a three time-point imaging study of white and gray matter degeneration. Amyotroph Lateral Scler Frontotemporal Degener. (2018) 19:232-41. doi: 10.1080/21678421.2017.1407795

18. Gordon P, Cheng B, Salachas F, Pradat P-F, Bruneteau G, Corcia P, et al. Progression in ALS is not linear but is curvilinear. J Neurol. (2010) 257:1713-7. doi: 10.1007/s00415-010-5609-1

19. Rooney J, Byrne S, Heverin M, Tobin K, Dick A, Donaghy C, et al. A multidisciplinary clinic approach improves survival in ALS: a comparative study of ALS in Ireland and Northern Ireland. J Neurol Neurosurg Psychiat. (2014) 86:481-2. doi: 10.1136/jnnp-2014-309601

20. Bede P, O’Brannagáin D, Lorenzl S, Oliver D, Hardiman O. Symptomatic Management and Palliative Care in Neurodegenerative Disease. Neurodegenerative Disorders. London: Springer (2011). p. 263-89. doi: 10.1007/978-1-84996-011-3-13

21. Mitsumoto $\mathrm{H}$, Brooks BR, Silani V. Clinical trials in amyotrophic lateral sclerosis: why so many negative trials and how can trials be improved? Lancet Neurol. (2014) 13:1127-38. doi: 10.1016/S1474-4422(14)70129-2

22. Bowser R, Turner MR, Shefner J. Biomarkers in amyotrophic lateral sclerosis: opportunities and limitations. Nat Rev Neurol. (2011) 7:631-8. doi: 10.1038/nrneurol.2011.151

23. Querin G, Bede P, El Mendili MM, Li M, Pelegrini-Issac M, Rinaldi $\mathrm{D}$, et al. Presymptomatic spinal cord pathology in c9orf72 mutation carriers: a longitudinal neuroimaging study. Ann Neurol. (2019) 86:158-67. doi: 10.1002/ana.25520

24. Benatar M, Wuu J. Presymptomatic studies in ALS: rationale, challenges, and approach. Neurology. (2012) 79:1732-9. doi: 10.1212/WNL.0b013e31826e9b1d

25. Bede P, Bokde ALW, Byrne S, Elamin M, McLaughlin RL, Kenna K, et al. Multiparametric MRI study of ALS stratified for the C9orf72 genotype. Neurology. (2013) 81:361-9. doi: 10.1212/WNL.0b013e31829c5eee

26. Bede P, Elamin M, Byrne S, McLaughlin RL, Kenna K, Vajda A, et al. Basal ganglia involvement in amyotrophic lateral sclerosis. Neurology. (2013) 81:2107-15. doi: 10.1212/01.wnl.0000437313.80913.2c

27. Menke RAL, Proudfoot M, Talbot K, Turner MR. The two-year progression of structural and functional cerebral MRI in amyotrophic lateral sclerosis. NeuroImage Clin. (2018) 17:953-61. doi: 10.1016/j.nicl.2017.12.025

28. Lebouteux MV, Franques J, Guillevin R, Delmont E, Lenglet T, Bede P, et al. Revisiting the spectrum of lower motor neuron diseases with snake eyes appearance on magnetic resonance imaging. Eur J Neurol. (2014) 21:1233-41. doi: 10.1111/ene.12465

29. Li Hi Shing S, Chipika RH, Finegan E, Murray D, Hardiman O, Bede P. Postpolio syndrome: more than just a lower motor neuron disease. Front Neurol. (2019) 10:773. doi: 10.3389/fneur.2019.00773

30. Bede P, Elamin M, Byrne S, Hardiman O. Sexual dimorphism in ALS: Exploring gender-specific neuroimaging signatures. Amyotroph Lateral Scler Frontotemporal Degener. (2013) 15:235-43. doi: 10.3109/21678421.2013.865749

31. Byrne S, Elamin M, Bede P, Shatunov A, Walsh C, Corr B, et al. Cognitive and clinical characteristics of patients with amyotrophic lateral sclerosis carrying a C9orf72 repeat expansion: a population-based cohort study. Lancet Neurol. (2012) 11:232-40. doi: 10.1016/S1474-4422(12)70014-5

32. Floeter MK, Katipally R, Kim MP, Schanz O, Stephen M, Danielian $\mathrm{L}$, et al. Impaired corticopontocerebellar tracts underlie pseudobulbar affect in motor neuron disorders. Neurology. (2014) 83:620-7. doi: 10.1212/WNL.0000000000000693

33. Bede P, Finegan E. Revisiting the pathoanatomy of pseudobulbar affect: mechanisms beyond corticobulbar dysfunction. Amyotroph Lateral Scler Frontotemporal Degener. (2018) 19:4-6. doi: 10.1080/21678421.2017. 1392578
34. Eisen A, Kiernan M, Mitsumoto H, Swash M. Amyotrophic lateral sclerosis: a long preclinical period? J Neurol Neurosurg Psychiat. (2014) 85:1232-8. doi: 10.1136/jnnp-2013-307135

35. Schuster C, Hardiman O, Bede P. Development of an automated MRI-based diagnostic protocol for amyotrophic lateral sclerosis using diseasespecific pathognomonic features: a quantitative disease-state classification study. PLoS ONE. (2016) 11:e0167331. doi: 10.1371/journal.pone. 0167331

36. Bede P, Bokde A, Elamin M, Byrne S, McLaughlin RL, Jordan N, et al. Grey matter correlates of clinical variables in amyotrophic lateral sclerosis (ALS): a neuroimaging study of ALS motor phenotype heterogeneity and cortical focality. J Neurol Neurosurg Psychiat. (2013) 84:766-73. doi: 10.1136/jnnp-2012-302674

37. Burke $T$, Elamin $M$, Bede $P$, Pinto-Grau $M$, Lonergan $K$, Hardiman $\mathrm{O}$, et al. Discordant performance on the 'Reading the Mind in the Eyes' Test, based on disease onset in amyotrophic lateral sclerosis. Amyotroph Lateral Scler Frontotemporal Degener. (2016) 17:467-2. doi: 10.1080/21678421.2016.1177088

38. Elamin M, Pinto-Grau M, Burke T, Bede P, Rooney J, O'Sullivan M, et al. Identifying behavioural changes in ALS: validation of the Beaumont Behavioural Inventory (BBI). Amyotroph Lateral Scler Frontotemporal Degener. (2017) 18:68-73. doi: 10.1080/21678421.2016.1248976

39. McLaughlin RL, Kenna KP, Vajda A, Bede P, Elamin M, Cronin $\mathrm{S}$, et al. Second-generation Irish genome-wide association study for amyotrophic lateral sclerosis. Neurobiol Aging. (2015) 36:1221.e7-13. doi: 10.1016/j.neurobiolaging.2014.08.030

40. Al-Chalabi A, Hardiman O. The epidemiology of ALS: a conspiracy of genes, environment and time. Nat Rev Neurol. (2013) 9:617-28. doi: 10.1038/nrneurol.2013.203

41. Bede P. Deciphering neurodegeneration: a paradigm shift from focality to connectivity. Neurology. (2017) 89:1758-9. doi: 10.1212/WNL.0000000000004582

42. Gorges M, Vercruysse P, Muller HP, Huppertz HJ, Rosenbohm A, Nagel G, et al. Hypothalamic atrophy is related to body mass index and age at onset in amyotrophic lateral sclerosis. J Neurol Neurosurg Psychiat. (2017) 88:1033-41. doi: 10.1136/jnnp-2017-315795

43. Lule D, Pauli S, Altintas E, Singer U, Merk T, Uttner I, et al. Emotional adjustment in amyotrophic lateral sclerosis (ALS). J Neurol. (2012) 259:33441. doi: 10.1007/s00415-011-6191-x

44. Lule D, Nonnenmacher S, Sorg S, Heimrath J, Hautzinger M, Meyer T, et al. Live and let die: existential decision processes in a fatal disease. J Neurol. (2014) 261:518-25. doi: 10.1007/s00415-013-7229-z

45. Lule D, Hacker S, Ludolph A, Birbaumer N, Kubler A. Depression and quality of life in patients with amyotrophic lateral sclerosis. Dtsch Arztebl Int. (2008) 105:397. doi: 10.3238/arztebl.2008.0397

46. Oliver D, Maguire S, Hardiman O, Bede P. Palliative care and end of life care. In: Hardiman O, Doherty C, Elamin M, Bede P. editors. Neurodegenerative Disorders. London: Springer (2016). p. 305-19. doi: 10.1007/978-3-319-23309-3 17

47. Bede P, Oliver D, Stodart J, van den Berg L, Simmons Z, D OB, et al. Palliative care in amyotrophic lateral sclerosis: a review of current international guidelines and initiatives. J Neurol Neurosurg Psychiat. (2011) 82:413-8. doi: 10.1136/jnnp.2010.232637

48. Christidi F, Karavasilis E, Ferentinos P, Xirou S, Velonakis G, Rentzos M, et al. Investigating the neuroanatomical substrate of pathological laughing and crying in amyotrophic lateral sclerosis with multimodal neuroimaging techniques. Amyotroph Lateral Scler Frontotemporal Degener. (2018) 19:1220. doi: 10.1080/21678421.2017.1386689

49. Schuster C, Hardiman O, Bede P. Survival prediction in Amyotrophic lateral sclerosis based on MRI measures and clinical characteristics. BMC Neurol. (2017) 17:73. doi: 10.1186/s12883-017-0854-x

50. Querin G, El Mendili MM, Bede P, Delphine S, Lenglet T, MarchandPauvert V, et al. Multimodal spinal cord MRI offers accurate diagnostic classification in ALS. J Neurol Neurosurg Psychiat. (2018) 89:1220-1. doi: 10.1136/jnnp-2017-317214

51. Elamin M, Bede P, Montuschi A, Pender N, Chio A, Hardiman O. Predicting prognosis in amyotrophic lateral sclerosis: a simple algorithm. J Neurol. (2015) 262:1447-54. doi: 10.1007/s00415-015-7731-6 
52. Phukan J, Elamin M, Bede P, Jordan N, Gallagher L, Byrne S, et al. The syndrome of cognitive impairment in amyotrophic lateral sclerosis: a population-based study. J Neurol Neurosurg Psychiat. (2012) 83:102-8. doi: 10.1136/jnnp-2011-300188

53. Geser F, Prvulovic D, O’Dwyer L, Hardiman O, Bede P, Bokde AL, et al. On the development of markers for pathological TDP-43 in amyotrophic lateral sclerosis with and without dementia. Progress Neurobiol. (2011) 95:649-62. doi: 10.1016/j.pneurobio.2011.08.011

54. Burke T, Pinto-Grau M, Lonergan K, Bede P, O'Sullivan M, Heverin M, et al. A Cross-sectional population-based investigation into behavioral change in amyotrophic lateral sclerosis: subphenotypes, staging, cognitive predictors, and survival. Ann Clin Trans Neurol. (2017) 4:305-17. doi: 10.1002/acn3.407

55. Burke T, Pinto-Grau M, Lonergan K, Elamin M, Bede P, Costello E, et al. Measurement of social cognition in amyotrophic lateral sclerosis: a population based study. PLoS ONE. (2016) 11:e0160850. doi: 10.1371/journal.pone.0160850

56. Elamin M, Bede P, Byrne S, Jordan N, Gallagher L, Wynne B, et al. Cognitive changes predict functional decline in ALS: a population-based longitudinal study. Neurology. (2013) 80:1590-7. doi: 10.1212/WNL.0b013e31828f18ac

57. Elamin M, Phukan J, Bede P, Jordan N, Byrne S, Pender N, et al. Executive dysfunction is a negative prognostic indicator in patients with ALS without dementia. Neurology. (2011) 76:1263-9. doi: 10.1212/WNL.0b013e318214359f

58. Burke T, Lonergan K, Pinto-Grau M, Elamin M, Bede P, Madden C, et al. Visual encoding, consolidation, and retrieval in amyotrophic lateral sclerosis: executive function as a mediator, and predictor of performance. Amyotroph Lateral Scler Frontotemporal Degener. (2017) 18:193-201. doi: 10.1080/21678421.2016.1272615

59. Christidi F, Zalonis I, Kyriazi S, Rentzos M, Karavasilis E, Wilde EA, et al. Uncinate fasciculus microstructure and verbal episodic memory in amyotrophic lateral sclerosis: a diffusion tensor imaging and neuropsychological study. Brain Imaging Behav. (2014) 8:497-505. doi: $10.1007 /$ s11682-013-9271-y

60. Christidi F, Migliaccio R, Santamaria-Garcia H, Santangelo G, Trojsi F. Social cognition dysfunctions in neurodegenerative diseases: neuroanatomical correlates and clinical implications. Behav Neurol. (2018) 2018:1849794. doi: 10.1155/2018/1849794

61. Iyer PM, Mohr K, Broderick M, Gavin B, Burke T, Bede P, et al. Mismatch negativity as an indicator of cognitive sub-domain dysfunction in amyotrophic lateral sclerosis. Front Neurol. (2017) 8:395. doi: 10.3389/fneur.2017.00395

62. Nasseroleslami B, Dukic S, Broderick M, Mohr K, Schuster C, Gavin B, et al. Characteristic increases in EEG connectivity correlate with changes of structural MRI in amyotrophic lateral sclerosis. Cereb Cortex. (2017) 29:27-41. doi: 10.1093/cercor/bhx301

63. Bede P, Elamin M, Byrne S, McLaughlin RL, Kenna K, Vajda A, et al. Patterns of cerebral and cerebellar white matter degeneration in ALS. $J$ Neurol Neurosurg Psychiat. (2015) 86:468-70. doi: 10.1136/jnnp-2014-30 8172

64. Tan RH, Devenney E, Dobson-Stone C, Kwok JB, Hodges JR, Kiernan $\mathrm{MC}$, et al. Cerebellar integrity in the amyotrophic lateral sclerosis - frontotemporal dementia continuum. PLoS ONE. (2014) 9:e105632. doi: 10.1371/journal.pone.0105632

65. Feron M, Couillandre A, Mseddi E, Termoz N, Abidi M, Bardinet E, et al. Extrapyramidal deficits in ALS: a combined biomechanical and neuroimaging study. J Neurol. (2018) 265:2125-36. doi: 10.1007/s00415-0188964-y

66. Pradat P-F, Bruneteau G, Munerati E, Salachas F, Le Forestier N, Lacomblez $\mathrm{L}$, et al. Extrapyramidal stiffness in patients with amyotrophic lateral sclerosis. Mov Disord. (2009) 24:2143-8. doi: 10.1002/mds.22762

67. Finegan E, Li Hi Shing S, Chipika RH, Doherty MA, Hengeveld JC, Vajda A, et al. Widespread subcortical grey matter degeneration in primary lateral sclerosis: a multimodal imaging study with genetic profiling. NeuroImage Clin. (2019) 24:102089. doi: 10.1016/j.nicl.2019.102089

68. Machts J, Loewe K, Kaufmann J, Jakubiczka S, Abdulla S, Petri S, et al. Basal ganglia pathology in ALS is associated with neuropsychological deficits. Neurology. (2015) 85:1301-9. doi: 10.1212/WNL.0000000000 002017
69. Christidi F, Karavasilis E, Rentzos M, Velonakis G, Zouvelou V, Xirou S, et al. Hippocampal pathology in Amyotrophic Lateral Sclerosis: selective vulnerability of subfields and their associated projections. Neurobiol Aging. (2019) 84:178-88. doi: 10.1016/j.neurobiolaging.2019.07.019

70. Bede P, Chipika RH, Finegan E, Shing SLH, Doherty MA, Hengeveld JC, et al. Brainstem pathology in amyotrophic lateral sclerosis and primary lateral sclerosis: a longitudinal neuroimaging study. NeuroImage Clin. (2019) 2019:102054. doi: 10.1016/j.nicl.2019.102054

71. Christidi F, Karavasilis E, Velonakis G, Rentzos M, Zambelis T, Zouvelou V, et al. Motor and extra-motor gray matter integrity may underlie neurophysiologic parameters of motor function in amyotrophic lateral sclerosis: a combined voxel-based morphometry and transcranial stimulation study. Brain Imaging Behav. (2018) 12:1730-41. doi: 10.1007/s11682-018-9841-0

72. Abidi M, de Marco G, Couillandre A, Feron M, Mseddi E, Termoz N, et al. Adaptive functional reorganization in amyotrophic lateral sclerosis: coexisting degenerative and compensatory changes. Eur J Neurol. (2019). doi: 10.1111/ene.14042. [Epub ahead of print].

73. Abrahams S, Goldstein LH, Simmons A, Brammer M, Williams SCR, Giampietro V, et al. Word retrieval in amyotrophic lateral sclerosis: a functional magnetic resonance imaging study. Brain. (2004) 127:1507-17. doi: 10.1093/brain/awh170

74. Christidi F, Karavasilis E, Zalonis I, Ferentinos P, Giavri Z, Wilde EA, et al. Memory-related white matter tract integrity in amyotrophic lateral sclerosis: an advanced neuroimaging and neuropsychological study. Neurobiol Aging. (2017) 49:69-78. doi: 10.1016/j.neurobiolaging.2016.09.014

75. Brettschneider J, Arai K, Del Tredici K, Toledo JB, Robinson JL, Lee EB, et al. TDP-43 pathology and neuronal loss in amyotrophic lateral sclerosis spinal cord. Acta Neuropathol. (2014) 128:423-37. doi: 10.1007/s00401-014-1299-6

76. Muller HP, Turner MR, Grosskreutz J, Abrahams S, Bede P, Govind V, et al. A large-scale multicentre cerebral diffusion tensor imaging study in amyotrophic lateral sclerosis. J Neurol Neurosurg Psychiat. (2016) 87:570-9. doi: 10.1136/jnnp-2015-311952

77. Kassubek J, Muller HP, Del Tredici K, Brettschneider J, Pinkhardt EH, Lule D, et al. Diffusion tensor imaging analysis of sequential spreading of disease in amyotrophic lateral sclerosis confirms patterns of TDP-43 pathology. Brain. (2014) 137:1733-40. doi: 10.1093/brain/awu090

78. Lule DE, Ludolph AC. In vivo tracking of TDP43 in ALS: cognition as a new biomarker for brain pathology. J Neurol Neurosurg Psychiat. (2019). doi: 10.1136/jnnp-2019-321940. [Epub ahead of print].

79. Westeneng HJ, Verstraete E, Walhout R, Schmidt R, Hendrikse J, Veldink JH, et al. Subcortical structures in amyotrophic lateral sclerosis. Neurobiol Aging. (2015) 36:1075-82. doi: 10.1016/j.neurobiolaging.2014.09.002

80. Schuster C, Elamin M, Hardiman O, Bede P. The segmental diffusivity profile of amyotrophic lateral sclerosis associated white matter degeneration. Eur J Neurol. (2016) 23:1361-71. doi: 10.1111/ene.13038

81. Bede P, Iyer PM, Schuster C, Elamin M, McLaughlin RL, Kenna K, et al. The selective anatomical vulnerability of ALS: 'disease-defining' and 'diseasedefying' brain regions. Amyotroph Lateral Scler Frontotemporal Degener. (2016) 17:561-70. doi: 10.3109/21678421.2016.1173702

82. Bede P. The histological correlates of imaging metrics: postmortem validation of in vivo findings. Amyotroph Lateral Scler Frontotemporal Degener. (2019) 20:457-60. doi: 10.1080/21678421.2019.1639195

83. Bede P, Hardiman O. Lessons of ALS imaging: pitfalls and future directions - a critical review. NeuroImage Clin. (2014) 4:436-43. doi: 10.1016/j.nicl.2014.02.011

84. Bede P, Querin G, Pradat PF. The changing landscape of motor neuron disease imaging: the transition from descriptive studies to precision clinical tools. Curr Opin Neurol. (2018) 31:431-8. doi: 10.1097/WCO.00000000000 00569

85. Bede P, Omer T, Finegan E, Chipika RH, Iyer PM, Doherty MA, et al. Connectivity-based characterisation of subcortical grey matter pathology in frontotemporal dementia and ALS: a multimodal neuroimaging study. Brain Imaging Behav. (2018) 12:1696-707. doi: 10.1007/s11682-018-9837-9

86. Bede P, Bokde AL, Byrne S, Elamin M, Fagan AJ, Hardiman O. Spinal cord markers in ALS: diagnostic and biomarker considerations. Amyotr Later Scler. (2012) 13:407-15. doi: 10.3109/17482968.2011. 649760 
87. Bede P, Walsh R, Fagan AJ, Hardiman O. "Sand-watch" spinal cord: a case of inferior cervical spinal cord atrophy. J Neurol. (2013) 261:235-7. doi: 10.1007/s00415-013-7193-7

88. Broad RJ, Gabel MC, Dowell NG, Schwartzman DJ, Seth AK, Zhang H, et al. Neurite orientation and dispersion density imaging (NODDI) detects cortical and corticospinal tract degeneration in ALS. J Neurol Neurosurg Psychiat. (2018) 90:404-11. doi: 10.1136/jnnp-2018-318830

89. Blasco H, Patin F, Descat A, Garcon G, Corcia P, Gele P, et al. A pharmaco-metabolomics approach in a clinical trial of ALS: Identification of predictive markers of progression. PLoS ONE. (2018) 13:e0198116. doi: 10.1371/journal.pone.0198116

90. Devos D, Moreau C, Kyheng M, Garcon G, Rolland AS, Blasco H, et al. A ferroptosis-based panel of prognostic biomarkers for Amyotrophic Lateral Sclerosis. Sci Rep. (2019) 9:2918. doi: 10.1038/s41598-019-39739-5

91. Bede P. From qualitative radiological cues to machine learning: MRIbased diagnosis in neurodegeneration. Fut Neurol. (2017) 12:5-8. doi: 10.2217/fnl-2016-0029
Conflict of Interest: PB is the patron of the Irish motor neuron disease association (IMNDA), the head of the computational neuroimaging group (CNG) in Trinity College Dublin, member of the steering committee of the Neuroimaging Society of ALS (NiSALS) and member of the biomedical research advisory panel of the UK MND association (MNDA). These affiliations had no impact on the opinions expressed herein.

P-FP denies any commercial or financial relationships that could be construed as conflict of interest.

Copyright (c) 2019 Bede and Pradat. This is an open-access article distributed under the terms of the Creative Commons Attribution License (CC BY). The use, distribution or reproduction in other forums is permitted, provided the original author(s) and the copyright owner(s) are credited and that the original publication in this journal is cited, in accordance with accepted academic practice. No use, distribution or reproduction is permitted which does not comply with these terms. 